\title{
A Socio-Ecological Exploration into Urban Form: The Environmental Costs of Travel
}

Dr. Zeenat Kotval-K $\mathrm{a}^{\mathrm{a}^{*}}$ and Dr. Igor Vojnovic ${ }^{\mathrm{b}}$

${ }^{a}$ Michigan State University

552 W. Circle Dr., Room 404

East Lansing, MI 48824

USA

Email: kotvalze@msu.edu

${ }^{*}$ Corresponding Author

${ }^{\mathrm{b}}$ Michigan State University

673 Auditorium Rd., Room 127

East Lansing, MI 48824

USA

Email:vojnovic@msu.edu

Acknowledgements: The authors would like to thank the U.S. National Science Foundation (NSF) for funding this research under the Human and Social Dynamics program grant SES 0624263. We would also like to thank the Michigan Secretary of State for supplemental data provided for this research, and our community partners, the City of Detroit's Planning and Development Department, the Michigan Suburbs Alliance, the Governor's Council on Physical Fitness, Health and Sports, U-SNAP-BAC and Messiah Housing Corporation for their support of this project. All findings and opinions are those of the authors and do not reflect the views of NSF. 


\section{INTRODUCTION}

Into the $21^{\text {st }}$ century, with the world population becoming urban, and with wealth and consumption continuing to concentrate in cities - and particularly in wealthy countriesincreasing interest has been placed on the socio-economic dimensions of expanding urban metabolisms and their environmental burdens (McGranahan and Satterthwaite, 2002; Rees, 1992; Vojnovic, 2014; Wackernagel and Rees, 1996). The relationship between income, consumption and environmental degradation began receiving particular attention after the publication of the World Commission on Environment and Development's (WCED) Our Common Future (1987). In response to the WCED, considerable political effort began to focus on framing a more socio-ecologically balanced global economy. This is partly evident in the over 10,000 cities and towns, across 113 countries, which have adopted Local Agenda 21 programs focused on mitigating negative anthropogenic impacts on the natural environment (Brugmann, 2013).

Globally, research, including publications by the World Bank and the United Nations, have illustrated the relationship between income, resource consumption, and resulting environmental burdens. According to the World Bank (2008), while the world's richest 20\% accounted for $76.6 \%$ of total private consumption, at the other end of the spectrum, the world's poorest $20 \%$ accounted for only $1.5 \%$ of total private consumption. This association between income and consumption has become a growing theme in the socio-ecological literature, with the ongoing recognition — conceptually and quantitatively — that a relatively small proportion of the global population, some $25 \%$ of the world's richest, are almost exclusively responsible for the detrimental impacts on Earth's ecological systems (Crutzen, 2002; Vojnovic, 2013). In addition, 
research also has shown that greater inequalities of power and wealth are in themselves responsible for increasing environmental degradation (Boyce, 1994; Boyce et al, 1999).

These broader global trends in income variation, consumption and environmental burdens have also translated into an assessment of local outcomes. William Rees' (1992) research on Canada's Lower Fraser Valley, explores local socio-ecological conditions in a high-income urban context. He shows that under conservative estimates, this region of 1,544 square miles in British Columbia, which includes the City of Vancouver, requires an area some 20 times greater than the region to meet local consumption. The resulting energy and material demands of this high-income population necessitates the import of extensive resources from outside of the region, and even Canada. Other research, including by Wackernagel and Rees (1996), Hedenus and Azar (2005), White (2007), Zhou and Imura (2011), and Jenerette et al (2006), also support the findings that there is considerable variability in consumption and environmental impacts between regions or nations, extensively shaped by income variations.

McGranahan and Satterthwaite (2002) developed a systematic conceptualization of the relationship between income, consumption and the nature of environmental burdens within cities. They argue that in low-income cities, with limited industries and low per capita and aggregate consumption, the populations maintain the least transfer of environmental burdens. The more limited environmental stresses associated with low-income cities also remain largely localized, evident in pressures such as inadequate sanitation, deficient water provision and poor air quality. In contrast, high-income cities, due to the high per capita and aggregate consumption, maintain the most widespread environmental burdens, which are the greatest threat to the planetary support systems. Yet as a result of the strict urban-environmental control measures and financial ability to adopt new technologies, the urban populations within high- 
income cities are generally able to ensure a high-quality urban environment, despite the widespread global environmental impacts from their high levels of consumption and waste production.

McGranahan and Satterthwaite also recognize that considerable variability in environmental burdens exists within any one of these classifications. They note that low-income cities have neighborhoods that maintain high-income consumption and environmental burden characteristics, and that high-income cities have poor neighborhoods with low-income consumption and environmental impact characteristics. The evidence of such variations in socioecological conditions within an urban region, however, are under-represented in the literature, generally because of the lack of fine-scale environmental data that would allow for intra-urban analyses.

This article will focus on exploring intra-regional consumption and environmental burden characteristics through the study of socio-economic variations of one particular human activity, travel within the Detroit region, Michigan. Greenhouse gas emissions from transportation have received extensive research interest over the last four decades. Accounting for about $27 \%$ of overall greenhouse gas emissions in the U.S., emissions from transportation have increased 16\% since 1990. Vehicle miles traveled by light-duty vehicles (the largest contributor to greenhouse gas emissions from the transportation industry) have increased by $35 \%$ since 1990 (EPA, 2013). In addition, according to the U.S. Department of Transportation (2006), the growth in transportation emissions accounts for $48 \%$ of the total growth in US greenhouse gas emissions since 1990. Light duty vehicles—including passenger cars and light duty trucks - contribute the largest share of greenhouse gas emissions, about 63\% in total (USDOT, 2006). The focus of this analysis is to explore how variations in urban form and in 
income, within and between Detroit area neighborhoods, affects travel and broader environmental impacts, specifically gasoline consumption and $\mathrm{CO}$ emissions.

In order to better understand the effects of urban form and class composition on travel, gasoline consumption and pollutant emissions at the neighborhood scale, this study focuses on three kinds of neighborhoods in the Detroit region: low-income urban Detroit neighborhoods (UD); more compact, upper-income suburban neighborhoods (CS); and low-density and dispersed, upper-income suburban neighborhoods (DS). The study provides a detailed socioeconomic exploration of travel by actual vehicle make and model, and the resulting environmental burdens within an urban region. This enables a rare exploration into the environmental burdens of private travel as shaped by urban form, class composition and vehicle ownership characteristics.

The research thus controls for the built environment and then uncovers the nuanced differences in travel behavior and environmental burdens. The research also employs a rare built environment-controlling data collection process. In order to control for the built environment, data is collected and analyzed at the neighborhood scale. Utilizing data on individual vehicle ownership characteristics and the full array of personal travel (work and non-work), allows for a unique exploration into the socio-ecological variations in travel within the Detroit region.

\section{The Economics of Urban Form: Assessing Costs}

Since the 1950s, considerable research interest has been placed on the economic and environmental impacts of urban form. Within just one decade, between 1950 and 1960, the use of urban land in U.S. urban areas increased twofold, yet the urban population increased by only 38\% (Boyce, 1963). In examining the costs of this evolving built environment, one line of 
research began to focus on infrastructure investment. This work consistently illustrated higher infrastructure and service delivery costs — assuming similar infrastructure standards — associated with post-war, lower-density developments when compared to pre-war, higher-density development patterns (Wheaton and Schussheim, 1955; Clawson, 1962; Boyce, 1963; RERC, 1974). The reduced costs realized with the higher-density, compact urban forms were evident with physical infrastructure provision and maintenance, including sidewalks, roads, water and sewer lines, and public transit. Research also began to reveal that it was the premature infrastructure investment on undeveloped land, and in cases heavily subsidized, which had facilitated the urban dispersion and the resulting increases in service costs (Vojnovic, 2000; 2006).

Added costs with the decentralizing urban form were also associated with the greater use of land in the production of built-space, as the lower-densities required more area to accommodate a given population. The increased urban infrastructure associated with lowerdensity developments also results in greater material and energy use in the construction and maintenance of the expanded provision of infrastructure. Accompanying these infrastructure investment and development practices, there was considerable degradation of the natural environment, and it was evident with higher levels of energy consumption, pollution emissions, waste production, and losses in sensitive ecosystems and biodiversity (Newman and Kenworthy 1989, 1999; SEMCOG, 1997; Vojnovic and Darden, 2013). In addition, this research illustrated the coupled dimension between economic and environmental costs in considering urban form. Encouraging more compact developments had both environmental and economic benefits.

Beyond the physical requirements in building different urban forms, research also began to illustrate that different built environments encouraged different characteristics in travel. 
Research by Peter Newman and Jeffrey Kenworthy $(1989 ; 1999)$ represented some of the early studies showing that more compact urban forms — characterized by higher-densities, mixed land use and highly-connected street networks_-facilitate travel over shorter distances and encourage non-motorized travel, thereby reducing gasoline consumption and pollutant emissions. Lowdensity, dispersed urban forms (as evident in Phoenix or Sacramento) maintain more resource intensive travel behavior, with greater gasoline use and associated automobile emissions (including $\mathrm{CO}_{\mathrm{x}}$ and $\mathrm{NO}_{\mathrm{x}}$ ) when compared to higher-density, compact urban forms (as evident in Boston or Chicago). For instance, Newman and Kenworthy (1999) show that while a typical New York City resident travels an average of 7,703 miles annually (generating 8,331 lbs of $\mathrm{CO}_{2}$ emissions associated with travel), a typical Houston resident travels 11,942 miles annually (generating 11,449 $\mathrm{lbs}$ of $\mathrm{CO}_{2}$ emissions).

More recent studies have continued to these findings between the built environment and fuel consumption. For example, Kim \& Brownstone (2013) find that there could be an $18 \%$ reduction in annual vehicle miles traveled (VMT) just by moving from a suburban to an urban area. In the study, lower levels of per capita gasoline consumption were also a result of households in denser areas using more fuel efficient vehicles. Similarly, Zahabi et al (2012) find that a $10 \%$ increase in density could result in a $3.5 \%$ decrease in greenhouse gas emissions.

Research on the impacts of socio-economic characteristics on trip generation, mode choice and VMT have also received considerable attention. While some studies focus on the built environment and socio-economic characteristics in exploring travel (Bailey, Mokhtarian \& Little, 2008; Ewing \& Cervero, 2001; Paulley et al, 2006; Stead, 2002), other emphasize specific characteristics of minority and disadvantaged populations (low-income, minority, women, children and the elderly) in analyzing travel behavior (Cao, Mokhtarian, \& Handy, 2010; Grengs, 
2012; Helling, 2000; Kim \& Ulfarsson, 2004; Matthies, Kuhn, \& Kloeckner, 2002; McDonald, 2005). Many of these studies find that lower-income residents tend to live in the inner city, as they are more reliant on public transit for their travel. Although this phenomena is slowly changing across the U.S., with upper-income groups moving back into the inner-city, ongoing decline in urban cores continues to characterize the U.S. Midwest, including Youngstown and Dayton (Ohio), Buffalo and Rochester (New York), and Saginaw, Flint and Detroit (Michigan).

Within this extensive literature on travel, however, studies on the impact of socioeconomic characteristics on environmental burdens in the U.S. are lacking. Bhat, Sen and Eluru (2009) in their comprehensive study on the impacts of various demographic, built environment, and vehicle characteristics on vehicle ownership and use in the San Francisco Bay Area, find that residents in higher-density neighborhoods are less likely to own and use large automobiles which in turn would lead to lower levels of fuel consumption and emissions. In the U.K., Brand and Preston (2010) have studied socio-economic characteristics and their impacts on emissions, and coined the " $60-20$ " emission rule, where $60 \%$ of the vehicular emissions were by the top $20 \%$ of emitters. Kotval-K and Vojnovic's recent study (2015) investigated the impacts of socioeconomic characteristics on energy consumption and pollutant emissions at a neighborhood level, utilizing Principal Components Analysis and regression analysis to specifically examine private automobile travel. The research shows that higher-income groups are associated with greater levels of environmental burdens, but this assessment excludes non-automobile travel options — specifically walking and public transit—prevalent in higher-density neighborhoods.

Impacts of fuel prices on the demand of fuel for transportation have also been examined in the literature on energy policy. Studies have shown that there is a " $U$ " trend in the elasticity of demand for fuel. Greening et al. (1995) examine the demand elasticity for fuel for different 
socio-economic groups (based on regional location, occupation and life-cycle) associated with increases in income and fuel price for a national sample. They found that different sub-groups, based on their occupation and life-cycle stages, had varied responses (in terms of gasoline consumption and vehicle miles traveled) to income and price changes. The traditional, white collar, nuclear family was found to be most responsive to fuel price changes, while the unemployed or retired people were most responsive to income changes. In general, however, non-economic variables were found to be most associated with a reduction in the demand for fuel and vehicle miles traveled. Wadud et al. (2009) performed a similar study on the income characteristics of households from a national sample. They find that the highest and lowest income quintiles have an inelastic demand for fuel based on income but highly elastic demand for fuel based on fuel price.

While some studies focus on national (and international) datasets to uncover the socioeconomic impacts of travel behavior or energy demand (Wadud et al., 2009; Wang \& Chen, 2014), other studies focus on city and metropolitan scales of analysis (Bhat \& Naumann, 2013; Boschmann \& Brady, 2013). Energy studies are generally performed at the county level (Parshall et al., 2010). This scale is used mainly due to the lack of availability of more detailed data, such as neighborhood level data (Dahl and Sterner, 1991; Sterner, Dahl \& Franzen, 1992). A majority of studies on travel behavior in the U.S. use the National Household Travel Survey (NHTS) dataset. This dataset is of a national random sample of residents and their travel behavior and vehicle characteristics. The low sampling levels in the NHTS, however, have been recognized as an obstacle for thorough studies on the topic (Holtzclaw et al., 2002; Lin \& Long, 2008). 
The following study on Detroit fills two gaps in the current literature. First, it looks at the socio-economic characteristics of residents and explores their environmental burdens associated with travel, and utilizing individual vehicles ownership data, with make, model, year and drivetrain characteristics. Second, the study is conducted at a neighborhood scale wherein the environmental burdens of a range of socio-economic sub-groups living within the same neighborhood type are analyzed. In addition, since little is known about built environment, travel and resulting environmental burdens of disadvantaged populations, this study also focuses on neighborhoods experiencing disinvestment and decline, allowing comparisons in travel, fuel consumption and pollutant emissions between lower-income and upper-income neighborhoods. Metropolitan or county level studies cannot explore the nuanced neighborhood level and sociodemographic travel, and resulting environmental impact characteristics, and with the advantage of actual vehicle ownership characteristics.

\section{MATERIAL AND METHODS}

Study Area

The study focuses on the Southeast Michigan Council of Governments (SEMCOG) Region, within which Detroit is the principal city. Detroit has transitioned from a vibrant and successful city in the first half of the $19^{\text {th }}$ century, to an urban center characterized by extreme decline and segregation by the $21^{\text {st }}$ century. The 2010 Census showed that the population of Detroit had decreased to $40 \%$ of its 1950 population peak of 1.85 million and is deeply segregated, with $83 \%$ of the population being African-American.

The study explores three neighborhood types — with each neighborhood consisting of about four square miles_-within the Detroit Region: low-income urban neighborhoods (UD) in 
the City of Detroit; higher-density, upper-income suburban neighborhoods (CS); and low-density and dispersed, upper-income suburban neighborhoods (DS). Two neighborhoods, in the lower eastside of Detroit form the first neighborhood type in this study. These neighborhoods have higher-density built environments, although they are characterized by severe disinvestment and decline, as evident with the population and the tax base exodus (Table 1).

The suburban neighborhoods, on the other hand, are thriving residential and commercial areas that have been successful in drawing people — and particularly the white population — away from the inner-city for a period that spans over six decades. Neighborhoods from the cities of Ann Arbor and Birmingham form the Compact Suburbs. These neighborhoods are older suburbs with higher-density built environments characteristic of pre-automobile development patterns. Finally, neighborhoods in Bloomfield Hills and West Bloomfield form the Dispersed Suburbs. These are newer, suburban areas with built environments traditionally associated with lowdensity, isolated, residential suburban enclaves. While Table 1 presents built environment characteristics by neighborhood type, Figure 1 maps their land uses. 
Table 1: Density, Connectivity and Land Use Mix by Neighborhood Type

\begin{tabular}{|lcrr|}
\hline & Urban Detroit & $\begin{array}{c}\text { Compact } \\
\text { Suburbs }\end{array}$ & $\begin{array}{c}\text { Dispersed } \\
\text { Suburbs }\end{array}$ \\
\hline \multicolumn{3}{|c|}{ Density (per square mile)* } \\
\hline $\begin{array}{l}\text { Population Density 2000 } \\
\text { Population Density 2008** }\end{array}$ & 6,314 & 4,696 & 1,797 \\
Population Density 2010 & 4,405 & 4,717 & 1,728 \\
& 3,928 & 4,723 & 1,711 \\
\hline \# of 4-way Intersections per & Connectivity (per square mile) & & \\
square mile & 84 & 46 & 8 \\
& Land Use Mix (per square mile) & & 614 \\
Single Family detached & 1,303 & 1,674 & 10 \\
Semi-detached home & 1 & 4 & 15 \\
Apartments & 4 & 35 & 30 \\
Townhomes/Rowhouses & 9 & 16 & 0 \\
Retail & 5 & 14 & 0 \\
Service & 28 & 32 & 0 \\
Public Institution & 23 & 16 & 0 \\
Industrial & 3 & 1 & \\
Visibly Abandoned Structures & 143 & 0 & \\
\hline
\end{tabular}

* Population density figures are calculated by dividing the total population for all the Census Tracts that encompass the study neighborhoods, by the size of the tracts (in square miles). The population figures are from the U.S. Census and the tract sizes were retrieved from the Michigan Center for Geographic Information site. Information from year 2000 is presented as the neighborhoods were chosen based on the 2000 Census, however, the survey collection was completed in 2008.

** Estimated density based on decade change values 
Figure 1: Land Use Characteristics of the Study Neighborhoods

\section{Detroit Neighborhood 1 Land Use Map}

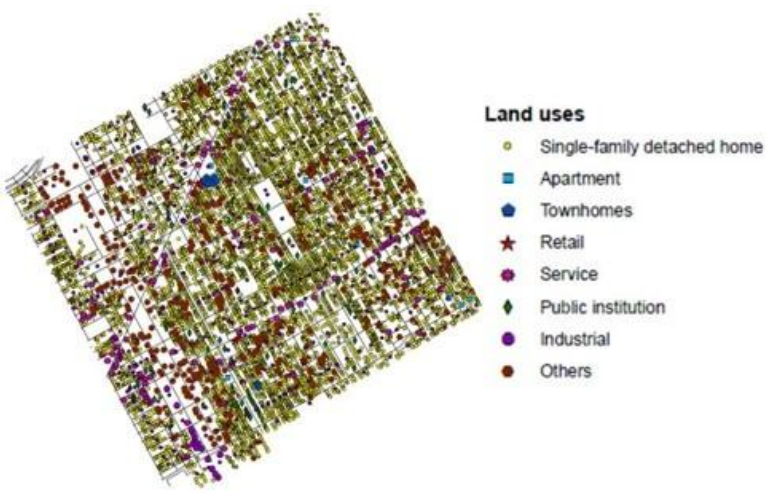

Ann Arbor Neighborhood Land Use Map
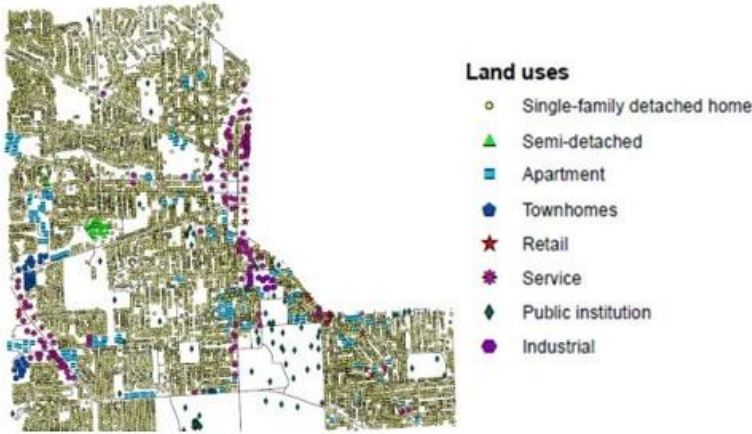

Bloomfield Hills Neighborhood Land Use Map

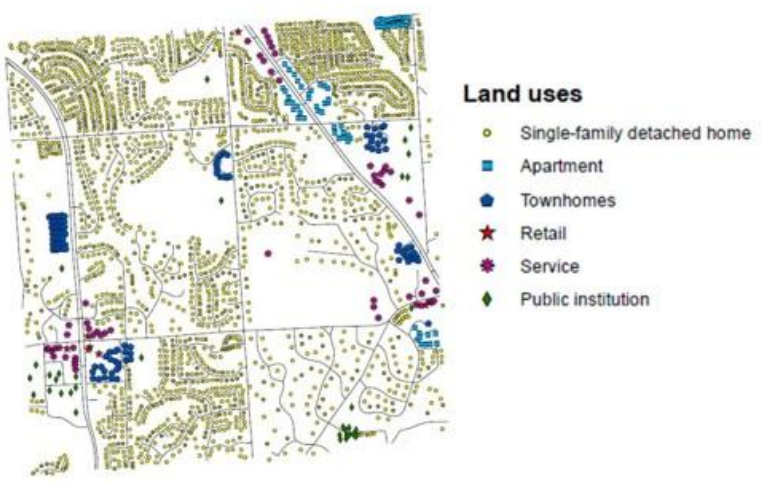

Detroit Neighborhood 2 Land Use Map

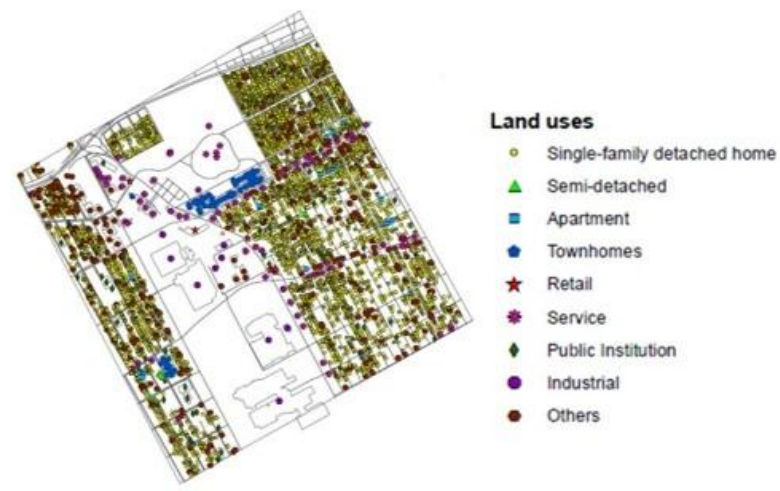

Birmingham Neighborhood Land Use Map

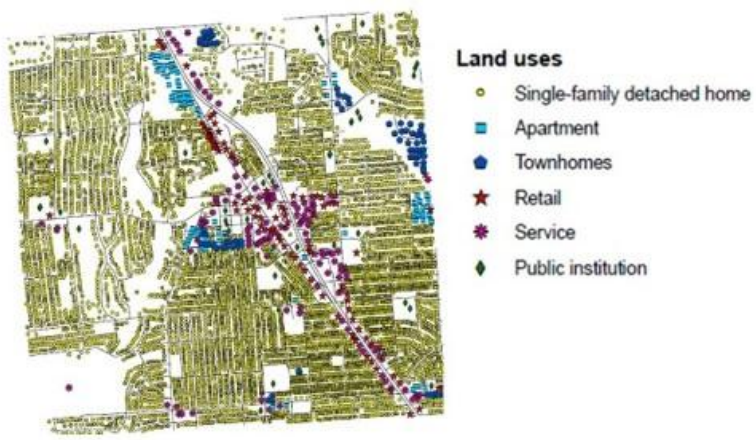

West Bloomfield Neighborhood Land Use Map

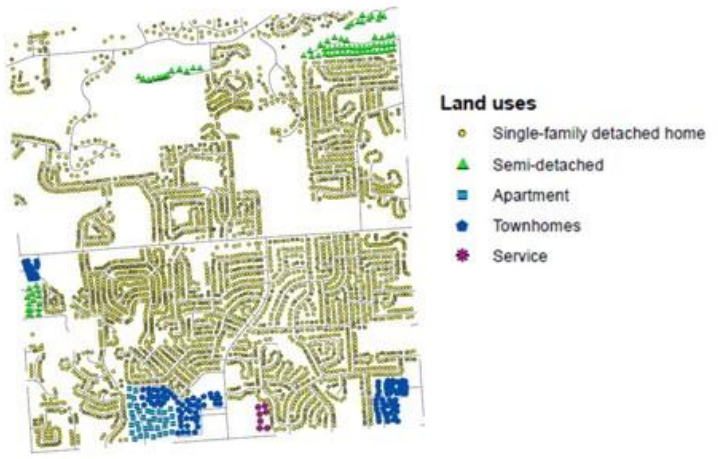


Data

A stratified random mail survey sent out in 2008 was used to collect data on travel behavior (travel mode, miles travelled, and frequency of travel), personal socio-economic variables and individual automobile ownership data. The survey was mailed in the second half of 2008, with the surveys being collected into early 2009. A $20 \%$ response rate, which is considered good for a mail survey, yielded 1,191 surveys (Sommer and Sommer, 1997; Zimowski et al, 1997). After removing surveys that had incomplete information, extreme outliers, and double responses from single households, this study included a total of 940 surveys.

The survey respondents were required to be at least 18 years old and were asked to report travel behavior over a typical week. All distance measures in the tables are to and from distances to destinations. The survey also collected data on independent socio-demographic variables, including race/ethnicity, age, gender, educational attainment, occupation, and household and personal income. Data were also collected on vehicle ownership, including make, model, age and various other vehicle details, such as engine and drivetrain characteristics. While U.S. Census data were used to identify the neighborhoods, the data collected in the survey offer variables - such as travel behavior to a full array of daily activities (school, shopping, personal service and leisure) and automobile ownership data - that are not collected by the Census Bureau or local municipal agencies. ${ }^{1}$

\footnotetext{
${ }^{1}$ The Census Bureau provides commute to work data through the American Community Survey program. As such it does not take into account the extensive travel for non-work purposes. In addition, the sampling levels for the Census commute to work data are relatively low. The National Household Travel Survey (NHTS) dataset by the U.S. Department of Transportation does include travel for all purposes, however, the sampling levels for that data are very low and Michigan does not have an 'add-on' program for that dataset. Individual vehicle ownership data are not available through the Census or NHTS.
} 
Data verification was integral to the project. With regard to distances, while the survey respondents were asked to indicate the distances between their home and various destinations, they were also asked for destination names and addresses. Any surveys that did not provide such information were removed from the analysis. Thus, since respondent addresses and travel destinations were known, the starting- and end-points of all trips were used in the analysis, some 15,400 weekly one-way trips. All locations (starting- and end-point destinations) were tracked, including through site surveys, and then geocoded. All trips were also referenced through Google Maps, using the algorithm for shortest time-route distance between destinations. Because there were considerable differences between self-reported and shortest time-route distances, this analysis used shortest time-route distances.

Data on vehicle characteristics were also verified with a database of vehicle ownership obtained through the Michigan Secretary of State. All vehicle ownership characteristics were matched with statewide vehicle registration data, so the exact make and model of the vehicles were verified. The individual vehicle characteristics were then matched to an Environmental Protection Agency (EPA) database where emissions and fuel efficiency was obtained for each specific make, model and year. While data was collected on carbon monoxide, nitrogen oxide, particulate matter, and non-metallic organic gasses, carbon monoxide $(\mathrm{CO})$ emissions were the only consistent emission recorded by the EPA across all the years of the vehicles owned by our respondents, hence the focus on $\mathrm{CO}$ emissions in this study.

Each type of neighborhood is divided into a lower-, middle- and upper-income grouping, based on the income distribution of the households in the neighborhoods (Table 2). Because the suburban residents had higher levels of income compared to the residents of Urban Detroit, the ternary splits are different. Socio-economic characteristics, travel behavior (for a full-array of 
travel, both work and non-work) and resulting environmental burdens, based on individual car ownership specifications, are assessed for each grouping. Again this enabled a unique control method for the built environment, since all data collection and analysis was at the neighborhood scale.

Table 2: Percentage of Households Split into the Three Income Groups

\begin{tabular}{|c|c|c|c|c|c|c|}
\hline $\begin{array}{l}\text { Household } \\
\text { Income Groups }\end{array}$ & \multicolumn{2}{|c|}{$\begin{array}{l}\text { Urban Detroit } \\
\text { (UD) }\end{array}$} & \multicolumn{2}{|c|}{$\begin{array}{c}\text { Compact Suburbs } \\
(C S)\end{array}$} & \multicolumn{2}{|c|}{$\begin{array}{c}\text { Dispersed Suburbs } \\
\text { (DS) }\end{array}$} \\
\hline & $\begin{array}{l}\text { Income } \\
\text { Range (in } \\
\text { O00s) }\end{array}$ & $\begin{array}{l}\text { \% of } \\
\text { House- } \\
\text { holds }\end{array}$ & $\begin{array}{l}\text { Income } \\
\text { Range (in } \\
\text { OOOs) }\end{array}$ & $\begin{array}{l}\text { \% of } \\
\text { House- } \\
\text { holds }\end{array}$ & $\begin{array}{l}\text { Income } \\
\text { Range (in } \\
\text { OOOs) }\end{array}$ & $\begin{array}{l}\text { \% of } \\
\text { House } \\
\text {-holds }\end{array}$ \\
\hline Low-Income & $\$ 5-\$ 45$ & $80 \%$ & $\$ 5-\$ 50$ & $19 \%$ & $\$ 5-\$ 50$ & $14 \%$ \\
\hline Middle-Income & $>\$ 45-\$ 90$ & $15 \%$ & $>\$ 50-\$ 100$ & $33 \%$ & $>\$ 50-\$ 100$ & $27 \%$ \\
\hline Upper-Income & $>\$ 90-\$ 135$ & $5 \%$ & $>\$ 100-\$ 155$ & $48 \%$ & $>\$ 100-\$ 155$ & $59 \%$ \\
\hline $\begin{array}{l}\text { Total Number } \\
\text { of Households }\end{array}$ & & 201 & & 347 & & 273 \\
\hline
\end{tabular}

Assessing differences in environmental burdens associated with travel behavior within each neighborhood type enabled two major contributions of this work. First, by controlling the built environment, the impacts of socio-economic characteristics on environmental burdens could be effectively teased out. Second, the neighborhoods consists of small geographic areas, 4-square-miles each, enabling the analysis to capture the nuances in travel behavior and environmental burdens without running the risk of averaging out large datasets, a common issue with studies covering larger geographical areas, such as in the case of a city, county or metro area.

Within these large-scale studies, exploring socio-economic characteristics, travel behavior and resulting environmental impacts averages the extensive, yet unique, variability that exists in neighborhoods within a city. In turn, one cannot assess the more nuanced variations in the socio-ecological condition of travel within an urban region. For instance, Wayne County- 
within which the City of Detroit is located-has 610 census tracts, which would be averaged-out and all nuance of socio-ecological conditions lost in a county-wide travel analysis. It is this interplay between the built environment and socio-ecological characteristics of travel at the intraregional scale — exploring differentials within and between neighborhoods — which is underrepresented in the literature. This study has enabled such an examination to take place because of this unique data collection and analysis process.

In addition, in computing environmental burdens, studies have also used average or typical vehicle specifications for gasoline consumption and pollutant emissions - constant values for a wide range of vehicles — which is particularly problematic when analyzing socio-economic impacts of travel. Substantial differences in the type of vehicles owned exists across socioeconomic groups, and these vehicles will have different characteristics, including in fuel efficiency and pollutant emissions, generating considerable variability in environmental burdens based on the specific vehicles owned and patterns in travel. It is thus at multiple-levels that this unique environment-controlling data collection and analysis process contributes to our understanding of the environmental burdens of travel as shaped by urban form, class composition and individual vehicle ownership characteristics within an urban region.

\section{RESULTS}

Table 3 shows a summary of travel behavior for all trip purposes (see Appendix B for travel behavior for work and non-work trip purposes) and basic vehicle characteristics by neighborhood type. These results will be analyzed in greater detail below, but some basic patterns start to become evident even within this aggregate neighborhood data, which continue to 
recur throughout the analysis. As densities increase, there is lower reliance on the car, which results in lower levels of gasoline consumption and pollutant emissions. In addition, as incomes decrease, there is lower reliance on the car, translating into lower levels of gasoline consumption and pollutant emissions. A large percentage of urban Detroit households, some 23\%, do not even own a car. Furthermore, with higher-incomes, cars tend to be newer-and hence more fuelefficient— but with higher-incomes the vehicles owned also tend to be larger and heavier, with bigger engines and all-wheel drive powertrains. Higher-incomes households have a tendency of buying all-wheel drive SUVs, minivans, and trucks.

Table 3: Summary of Travel Behavior by Neighborhood Type

\begin{tabular}{|c|c|c|c|}
\hline Household Income & $U D$ & CS & $L S$ \\
\hline \multicolumn{4}{|l|}{ Mode Choice (Average per Respondent) } \\
\hline$\%$ All Trips by Walking & 23.0 & 20.1 & 6.9 \\
\hline$\%$ All Trips by Transit & 9.8 & 2.8 & 0.2 \\
\hline$\%$ All Trips by Driving & 67.2 & 77.1 & 92.9 \\
\hline \multicolumn{4}{|c|}{ Average Annual Distances in miles (end- and return- destination trips) } \\
\hline All Trips by Walking & 746.1 & 381.4 & 247.7 \\
\hline All Trips by Transit & 808.8 & 116.9 & 8.9 \\
\hline All Trips by Driving & 4228.3 & 4254.2 & 8219.6 \\
\hline \multicolumn{4}{|l|}{ Vehicle Ownership } \\
\hline No. of vehicles in Household & 1.0 & 2.0 & 2.2 \\
\hline Vehicle Year & 1999 & 2002 & 2004 \\
\hline$\%$ Vehicles that are SUVs, Minivans or Trucks & $26 \%$ & $32 \%$ & $40 \%$ \\
\hline$\%$ of Households with no access to a vehicle & $23 \%$ & $2 \%$ & $0 \%$ \\
\hline \multicolumn{4}{|c|}{ Average Annual Environmental Burdens per Capita* } \\
\hline Fuel Consumption (gallons) & 198.6 & 197.1 & 409.3 \\
\hline CO Emissions (grams) & 18058.5 & 17410.9 & 34621.5 \\
\hline Avg. Fleet Fuel Economy (miles per gallon) & 21.3 & 21.6 & 20.1 \\
\hline Avg. Fleet CO Emissions (grams per mile) & 4.3 & 4.1 & 4.2 \\
\hline
\end{tabular}

*The environmental burdens calculations are a result of both end- and return-destination trips.

\section{Urban Detroit}


The UD neighborhoods largely consist of lower-income, predominantly AfricanAmerican residents. Low house prices were the dominant reason for respondents staying in these neighborhoods. In many instances, these homes were family homes that were inherited. These residents are typical of lower eastside Detroit residents, with the neighborhoods experiencing severe disinvestment and decline. ${ }^{2}$

The table shows that there were only 18 White respondents in these neighborhoods, making up $8.3 \%$ of the total respondents. The majority of the respondents were African American, who made up over $90 \%$ of the survey respondents. Another striking feature is the 'Employment,' with only $37 \%$ of the respondents employed for wages.

The UD neighborhoods have a heavy concentration of respondents in the lowest income grouping. About $80 \%$ of the respondents are in the lowest income category, while only $5 \%$ fall in the highest income category (table 2). The mean household income for the respondents in these neighborhoods is $\$ 30,423$, which falls in the lowest third of the income range in these neighborhoods.

\footnotetext{
${ }^{2}$ Appendix A has some descriptions of the categorical variables used in the analyses.
} 
Table 4: Trip Frequency, Annual Miles by Mode of Travel (Average per Respondent), and Vehicle Ownership

\begin{tabular}{|c|c|c|c|c|c|c|c|c|c|c|c|c|}
\hline & \multicolumn{4}{|c|}{ Urban Detroit } & \multicolumn{4}{|c|}{ Compact Suburbs } & \multicolumn{4}{|c|}{ Dispersed Suburbs } \\
\hline Income Group & Lower & Middle & Upper & $\begin{array}{l}\text { UD } \\
\text { Avg. }\end{array}$ & Lower & Middle & Upper & $\begin{array}{l}\text { CS } \\
\text { Avg. }\end{array}$ & Lower & Middle & Upper & $\begin{array}{l}\text { DS } \\
\text { Avg. }\end{array}$ \\
\hline \multicolumn{13}{|l|}{ Trip Frequency } \\
\hline$\%$ All Trips by Walking & 26.8 & 13.7 & 6.8 & 23.0 & 29.3 & 19.0 & 18.1 & 20.1 & 9.0 & 6.8 & 6.5 & 6.9 \\
\hline \% All Trips by Transit & 10.7 & 4.4 & 7.1 & 9.8 & 8.4 & 2.0 & 1.6 & 2.8 & 0 & 0.4 & 0.2 & 0.2 \\
\hline$\%$ All Trips by Driving & 62.5 & 81.9 & 86.1 & 67.2 & 62.3 & 79.1 & 80.3 & 77.1 & 91.0 & 92.8 & 93.4 & 92.9 \\
\hline \multicolumn{13}{|c|}{ Average Annual Miles to end-and return-destination trips } \\
\hline All Trips by Walking & 500.3 & 2123.8 & 427.0 & 746.1 & 373.2 & 270.2 & 460.6 & 381.4 & 39.4 & 282.8 & 281.8 & 247.7 \\
\hline All Trips by Transit & 589.2 & 2064.2 & 438.0 & 808.8 & 203.1 & 64.3 & 118.3 & 116.9 & 0.0 & 15.4 & 8.0 & 8.9 \\
\hline All Trips by Driving & 2892.1 & 9311.7 & 10771.3 & 4228.3 & 2098.0 & 4560.4 & 4910.1 & 4254.2 & 3980.3 & 6784.3 & 9915.1 & 8219.6 \\
\hline \multicolumn{13}{|l|}{ Vehicle Ownership } \\
\hline $\begin{array}{l}\text { No. of Vehicles in } \\
\text { Household }\end{array}$ & 0.8 & 1.6 & 1.8 & 1.0 & 1.4 & 1.9 & 2.2 & 2.0 & 1.7 & 2.0 & 2.4 & 2.2 \\
\hline Vehicle Year & 1998 & 2002 & 2002 & 1999 & 2000 & 2001 & 2003 & 2002 & 2003 & 2004 & 2004 & 2004 \\
\hline $\begin{array}{l}\% \text { of vehicles that are } \\
\text { Minivans/SUVs/Trucks }\end{array}$ & $22 \%$ & $30 \%$ & $37 \%$ & $26 \%$ & $25 \%$ & $31 \%$ & $37 \%$ & $32 \%$ & $23 \%$ & $36 \%$ & $54 \%$ & $40 \%$ \\
\hline $\begin{array}{l}\% \text { of Households with } \\
\text { no access to a vehicle }\end{array}$ & $27 \%$ & $6 \%$ & $11 \%$ & $23 \%$ & $9 \%$ & $1 \%$ & $0 \%$ & $2 \%$ & $0 \%$ & $0 \%$ & $0 \%$ & $0 \%$ \\
\hline
\end{tabular}


Table 4 shows that the lowest income range in UD neighborhoods, with $80 \%$ of the population, has access to less than one car per household, and the cars are about 10 years old on average. The highest earning, $5 \%$ of the respondents, have access to just under 2 cars per household and have newer cars (7 years old on average). Demographic characteristics show that there is not a difference in the age of the respondents across the income classes, nor a difference in the number of dependents in the household. There is a visible difference, however, in the years of education received. The respondents in the lowest-income range have an average of 13 years of education (completed high school), while the ones in the highest income range have an average of 16 years of education (college graduates).

Mode of travel by income group paints an interesting picture. For work trips (Appendix C) in Urban Detroit, the respondents in the upper income category rely solely on driving as the mode of travel, while those in the lowest income range conduct two-thirds of their trips to work by driving. Those in the lowest income category undertake about $16 \%$ of work-trips by walking and use transit for about another $16 \%$ of work-trips.

For non-work trips (Appendix C), the upper income range respondents use driving as the mode for about $81 \%$ of the trips within the urban neighborhoods. These respondents walk for $12 \%$ of their trips and use transit for $7 \%$ of their trips. This is quite a different travel pattern from the lowest income category. For non-work trips, respondents in the lowest income category use driving for about $63 \%$ of the trips to non-work destinations, while they use transit for $9 \%$ and walk for another $28 \%$ of their trips. 
Table 5: Average Annual Environmental Burdens

\begin{tabular}{|c|c|c|c|c|c|c|c|c|c|c|c|c|}
\hline & \multicolumn{4}{|c|}{ Urban Detroit } & \multicolumn{4}{|c|}{ Compact Suburbs } & \multicolumn{4}{|c|}{ Dispersed Suburbs } \\
\hline Income Group & Lower & Middle & Upper & $\begin{array}{l}\text { UD } \\
\text { Avg. }\end{array}$ & Lower & Middle & Upper & $\begin{array}{l}\text { CS } \\
\text { Avg. }\end{array}$ & Lower & Middle & Upper & $\begin{array}{l}\text { DS } \\
\text { Avg. }\end{array}$ \\
\hline $\begin{array}{l}\text { Fuel Consumption* } \\
\text { (gallons) }\end{array}$ & 133 & 454 & 529 & 199 & 91 & 209 & 237 & 197 & 189.5 & 327.9 & 517.1 & 409 \\
\hline $\begin{array}{l}\text { CO Emissions* } \\
\text { (grams) }\end{array}$ & 12338 & 41065 & 46990 & 18059 & 8419 & 19103 & 20125 & 17411 & 15990 & 28868 & 41895 & 34622 \\
\hline $\begin{array}{l}\text { Avg. Fleet Fuel } \\
\text { Economy (miles) }\end{array}$ & 21.7 & 20.5 & 20.4 & 21.3 & 23 & 21.8 & 20.7 & 21.6 & 21.0 & 20.7 & 19.2 & 20.1 \\
\hline $\begin{array}{l}\text { Avg. Fleet CO } \\
\text { Emissions (grams) }\end{array}$ & 4.3 & 4.4 & 4.4 & 4.3 & 4.0 & 4.2 & 4.1 & 4.1 & 4.0 & 4.3 & 4.2 & 4.2 \\
\hline
\end{tabular}

*The fuel consumption and emissions calculations are a result of both end- and return-destination trips. 
The reliance of the higher-income Urban Detroit residents on the car for all of their work trips clearly reflects distance to their jobs. These residents travel over 6,400 miles on average per year (123 miles per week) to and from work destinations in their cars, while the lowest income range residents travel about 895 miles per year (17 miles per week) in their vehicles (Appendix C). Higher-income residents have jobs further from their homes. The longer distances among the higher-income earners implies that many are likely driving into the Detroit CBD or into the suburbs for their employment.

The lowest-income residents either do not have the educational qualifications and many do not have access to vehicles to accept the jobs in the CBD or outside the city limits. A much larger number of the low-income urban Detroit residents are also unemployed, with $14 \%$ in the lowest-income category unemployed, $3 \%$ in the middle-income category unemployed, and $0 \%$ in the upper-income UD category unemployed.

Lastly, for all trip purposes, the upper-income UD residents travel over 3.7 times the average annual distance by car when compared to the lowest-income residents. Consequently, they have about 3.5 times the annual fuel consumption and the annual carbon emissions as that of the lowest-income range residents (Table 5). The wealthier respondents have newer, and more technologically advanced vehicles, but also tend to drive more trucks, SUVs, and minivans, ensuring higher gasoline consumption and pollutant emissions as incomes increase.

\section{Discussion}


The analyses of the UD neighborhoods reveal a number of important characteristics in travel. The main revelation is that even the very few residents with higher socio-economic characteristics have a remarkably different travel pattern than the more typical, lower-income residents. They have jobs that are further away, perhaps in the Detroit CBD or in the suburbs, and exercise the option to travel with their vehicles for most trips. Respondents in the lowestincome grouping have jobs that are closer and are more restricted by income, resulting in fewer trips by car. Many of the residents are unemployed. This is reflected in the fact that they do not have access to cars and are relegated to travel to nearer destinations. In the Urban Detroit neighborhoods, on average, the higher-income residents travel about three times the annual distance to work in comparison to the lower-income residents.

The urban residents face a situation where they have limited choices when it comes to shopping and service availability. Shopping for food is a necessity, however, the residents in the urban neighborhoods have to travel further to get to supermarkets that are located outside of their neighborhoods, and even forced to travel into surrounding suburbs. With the neighborhoods experiencing severe disinvestment and decline, many basic amenities—whether major supermarket chains or personal services such as banks or pharmacies - are closing-down within these communities. Hence, accessibility to many necessary daily destinations within these neighborhoods is being reduced, despite their higher-densities, high-connectivity, and mixed land uses.

From an environmental burdens perspective, the neighborhood establishes a pattern that is consistent among all neighborhood types: higher-income residents are responsible for higher levels of gasoline consumption and higher pollutant emissions. The highest-income subgroup drives about 3.5 times the distance in comparison to the lowest-income sub-group. Accordingly, 
the highest-income grouping consumes 3.4 times the annual fuel (annual average gallons per respondent) and emits 3.8 times the carbon monoxide (annual average grams per respondent) than the lowest-income grouping in the UD neighborhoods. At the same time, middle-income respondents in the urban neighborhoods-while consuming less petroleum and emitting fewer $\mathrm{CO}$ emissions than the upper-income respondents - consume more fuel and maintain higher $\mathrm{CO}$ emissions than the lowest-income respondents.

As far as the average fuel economy of the fleet of vehicles that each income group in Urban Detroit owns, it becomes evident that the average fuel economy decreases as one moves from the lower-income grouping to the upper-income grouping, despite the fact that the upperincome grouping drives newer and more technologically advanced vehicles. Similarly, the average fleet carbon monoxide emissions per respondent also increase from the lower-income to the upper-income groupings, from 4.3 grams per mile for the lower-income group fleet, to 4.4 grams per mile for the middle- and upper-income fleet. This analysis shows that the greater reliance on the car, the ownership of bigger and heavier vehicles, and the longer driving distances by upper-income groups counters any efficiency advantages from the adoption of newer and more fuel-efficient technologies.

\section{Compact Suburban Neighborhoods—Ann Arbor and Birmingham}

In terms of built environment characteristics, the CS neighborhoods are similar to the UD neighborhoods. These are relatively high-density neighborhoods for the Michigan context, with grid pattern road networks, and characterized by mixed land uses. Looking at the sociodemographic characteristics of residents in the CS neighborhoods, they are predominantly white, 
and they have higher-incomes and greater education than the residents of the UD neighborhoods. Thus, while the built environment characteristics of the CS neighborhoods are similar to the UD neighborhoods, the socio-demographic characteristics of CS residents are similar to the DS neighborhoods. ${ }^{3}$

The CS neighborhoods have a low number of African American respondents, seven who make-up $1.8 \%$ of the total number of respondents. However, there are a greater number of 'other' races in these neighborhoods when compared to the UD neighborhoods. The CS neighborhoods have $93.7 \%$ white respondents, $1.8 \%$ African American respondents and $4.5 \%$ of the respondents belong to 'Other' races. Two-thirds of the respondents were employed for wages. A significant portion of the unemployed are retired residents and stay-at-home parents.

Similar to the analysis of the urban neighborhoods, a breakdown of the respondents of the higher-density suburban neighborhoods into income groupings (Table 2) allows for further texture into the analysis of the socio-economics of travel and resulting impacts on gasoline consumption and $\mathrm{CO}$ emissions. Almost half of the respondents (48\%) fall into the highest onethird category of household income and only $19 \%$ fall into the lowest one-third household income category. The average household income for all the respondents in this neighborhood type was $\$ 95,920$. Table 4 gives a more detailed look at the characteristics of these three groups of respondents within the higher-density suburbs.

The upper-income group has newer and more vehicles. Also relevant is that the number of dependents increases with household income. The upper-income range residents have about 3 people that their income supports, and a child under the age of 18 years living at home, while the

\footnotetext{
${ }^{3}$ Appendix A has descriptions of the categorical variables used in the analyses.
} 
lowest-income range respondents support less than 2 people, and most of these households do not have any children under the age of 18 years living at home.

Table 4 shows the travel patterns of the residents within each income group for all trip purposes combined. With regard to travel mode, the middle- and upper-income residents behave similarly, both groups being highly automobile dependent. For work trips (Appendix C), the lower-income residents walk twice as much and they use public transit 7 times more when compared to the middle- and upper-income residents.

The non-work trips (Appendix C) show more subtle differences. The lowest-income residents walk for $32 \%$ of their non-work trips, while the upper-income residents walk for $19 \%$ of their non-work trips. The lowest-income residents also use transit for $3.7 \%$ of the non-work trips while the upper-income residents use it for less than $1 \%$ of their non-work trips.

In examining annual miles traveled by different travel modes, table 4 shows an interesting trend. The middle- and upper-income residents do not travel similar distances even though their mode choice is similar. The upper-income residents travel longer distances by walking and public transit than the middle-income residents. In fact, upper-income residents walk the longest annual distances. The lowest-income residents walk more and travel longer distances by walking when compared to middle-income respondents. However, upper-income residents travel about 5.8 times the amount that the lower-income residents do for work purposes annually by car (Appendix C).

The upper-income residents in the CS neighborhoods travel slightly more in distance than the lower-income residents do for non-work trips (Appendix C), and as a result, the total annual distance traveled for all trip purposes (Table 4) shows the upper-income residents travelling 
about 2.3 times the distance that the lower income residents do by car. The environmental burdens table (Table 5) shows a consistent trend. Upper-income residents consume about 2.6 times the fuel and emit about 2.4 times the pollutants. Similar to the environmental burden patterns among UD neighborhoods, the wealthier drive more, consume more gasoline, and are responsible for higher amounts of pollutant emissions, all while controlling for built environment characteristics.

\section{Discussion}

The CS neighborhoods maintain a tempered variation of travel evident in the UD neighborhoods; similar patterns in travel by socio-demographic composition but more subtle variability between income groups. The CS neighborhoods are robust communities in dynamic and wealthy Detroit suburbs, with strong urban cores, a rich land use mix and connected street networks.

The CS neighborhoods show that middle- and upper-income respondents have very similar patterns in mode of travel, but the distance traveled are different. The upper-income respondents walked further distances annually to all trips when compared to middle- and lowincome residents. In the CS neighborhoods, the higher-income range residents drove over 5.8 times the average annual distance to work when compared to the lower-income residents. The upper-income range respondents drove 2.3 times the distances of the lower-income range respondents for all trips, a substantial variation in travel patterns.

The average fuel economy for the fleet in the CS neighborhoods shows what emerges as a standard pattern throughout the study, higher-income groups, despite having newer vehicles, 
own vehicles that contribute to higher levels of environmental burdens. Wealthier residents in CS neighborhoods have a larger percentage (37\%) of SUVs, minivans and trucks in their fleet than the lower income residents (25\%). Correspondingly, fuel consumption varies from 23 miles per gallon for the lower-income group fleet, to 21.8 miles per gallon for the middle-income group and 20.7 miles per gallon for the upper-income group fleet. The average carbon monoxide emissions range from 4.0 grams per mile for the lower income-group fleet, to 4.2 grams per mile for the middle-income fleet and 4.1 grams per mile for the upper-income group fleet. The CS neighborhoods show, once again, that the wealthiest disproportionately contribute to environmental burdens within the neighborhoods, driving the longest distances, and owning vehicles with the highest fuel consumption and pollutant emissions. In contrast, lower-income groups maintain the least environmental burdens, shaped by both the vehicles they own and their patterns of travel.

\section{Dispersed Suburban Neighborhoods—Bloomfield Hills and West Bloomfield}

The built environment in the low-density, Dispersed Suburbs is very different from the UD and CS neighborhoods. These are the low-density neighborhoods, dominated by single land uses, predominantly residential, and are disconnected, being developed around the curvilinear street system. The socio-economic characteristics of the residents also show a less diverse class composition. The incomes are high, and as might be expected given the built environment and incomes, the travel behavior of these respondents is heavily automobile-dependent. In addition, transit is virtually non-existent in these neighborhoods. ${ }^{4}$

\footnotetext{
${ }^{4}$ Appendix A below shows a breakup of the categorical variables used in the analyses.
} 
However, these neighborhoods do have a greater ethnic mix of residents than the UD and CS neighborhoods. Whites make-up about $89 \%$ of the respondents, African Americans compose $3.5 \%$ of the respondents and other races make up the remaining $7.5 \%$ in the DS neighborhoods. Some $60 \%$ of the respondents were employed for wages, reflecting a higher number of stay at home parents.

The concentration of the wealth in the sprawling suburban neighborhoods becomes evident in table 2 and appendix A. Over half of the respondents (59\%) fall into the highest onethird of the household income range, while only $14 \%$ are in the lowest one-third of the household income range. The average household income for this neighborhood type was $\$ 108,164$; the highest average income among the three neighborhood types.

The range in vehicle characteristics among the three income groups, table 4, shows an expected trend. The higher the income, the greater the number of cars in the household and the newer the cars. The range of vehicle characteristics (such as the number of vehicles and age of the vehicle) between the low- and the upper-income groups is not significant. However, table 4 also shows that the highest-income residents have $54 \%$ of their vehicle fleet comprised of SUVs, minivans and trucks, while the lower-income residents have $23 \%$ of their fleet comprised of these vehicles.

With respect to mode of travel, Table 4 shows relatively homogenous travel behavior by the respondents of all three income groups for all trip purposes combined. When looking at this by trip purpose (Appendix C), respondents in the lowest-income group walk for about $9 \%$ of their non-work trips, while upper-income respondents walk for about $6 \%$ of their non-work trips. 
Most of the travel in this type of neighborhood, regardless of income, is by car. This was the only neighborhood type where all households had access to a car.

Despite the widespread automobile ownership, the annual miles traveled shows considerable variability by class (Table 4). Respondents in the upper-income grouping travel farther distances by car for all trip purposes. The greatest variance is for work trips (Appendix C), where the upper-income group travels over 8.9 times the total distance that the lower-income group travels. For non-work trips (Appendix C), the upper-income group travels a distance that is 1.2 times greater than the total distance that the lower-income group travels. For all trips combined, the upper-income group travels 2.5 times the total annual distance in comparison to the lower-income group.

The table on environmental burdens (Table 5) shows a familiar outcome. The upperincome group consumes about 2.7 times the annual fuel in comparison to the lower-income group. The pollutant emissions show similar trends, with the respondents in the upper-income group emitting about 2.6 times the annual carbon monoxide levels when compared to respondents in the lower-income group. Apart from the variance in travel, the higher pollutant emissions among the wealthier is attributed to the upper-income group having larger vehicles with more powerful engines, requiring more fuel and generating higher emissions.

\section{Discussion}

For the DS neighborhoods, it is recognized from the built environment objective data that these are large homes on large lots in isolated residential neighborhoods. These are generally expensive homes in exclusive neighborhoods. The residents of these neighborhoods are higher- 
income earners who are willing to drive long distances to work, as evident in time and distance, in order to attain the particular quality of life desired.

In the DS neighborhoods, the higher-income residents traveled over 8.9 times the average total annual distance to work when compared to the lower-income residents. Respondents in the upper-income group were also responsible for about 2.7 times the fuel consumption and 2.6 times the carbon monoxide pollutant emissions when compared to the respondents in the lowerincome group. The proportionate increases in fuel consumption and emissions are also shaped by the vehicle characteristics. On average, the lower-income subgroup fleet fuel efficiency is about 21 miles per gallon, while it is 20.7 miles per gallon for the middle-income subgroup fleet and 19.2 miles per gallon for the upper-income subgroup fleet. The average carbon monoxide emissions range from 4.0 grams per mile for the low-income fleet, to 4.3 grams per mile for the middle-income fleet and 4.2 grams per mile for the upper-income fleet. These figures all point to the fact that as income increases, vehicles tend to be larger, more powerful and require more energy in travel. Again, this positive trend between increasing environmental burdens and incomes is captured despite the fact that lower-income groups have older vehicles that due to their lower technical sophistication will tend to generate lower MPGs and higher CO emissions.

\section{CONCLUSIONS}

This Detroit region study explored the socio-economics of travel and resulting environmental burdens within three types of neighborhoods. The results consistently indicate that higher-income earners drive greater distances, consume more fuel and are responsible for higher levels of emissions than lower-income households, even when they live within the same neighborhoods. This is a unique contribution of this analysis, since we are controlling for the 
built environment and using performance characteristics of actual vehicles owned—with specific weight, engine, and power traits, best case emission levels pertaining to the specific make, model and year of the vehicle — and assigning them across a full array of driving destinations, including work and non-work trips.

An important contribution of this work is bringing socio-ecological conditions within an urban region to the forefront of travel behavior analysis. The class dimension of travel and resulting environmental burdens within an urban region is underrepresented in the existing literature. A general pattern emerges from the analysis, where the wealthier population subgroups, whether they live in robust communities or in neighborhoods experiencing disinvestment and decline, travel more often, and drive further distances — with bigger and heavier vehiclesand are responsible for higher levels of environmental burdens. These patterns are also evident with just the car ownership data. Across the three neighborhood types, while about $59 \%$ of the households earning less than $\$ 10,000$ in annual income do not own a vehicle, more than $99 \%$ of the households earning over $\$ 100,000$ in annual household income do own a vehicle. Moreover, while only $20 \%$ of the households earning less than $\$ 10,000$ in annual household income own larger-sized vehicles such as SUVs, minivans or trucks, $45 \%$ of households earning over $\$ 100,000$ in annual household income own such larger vehicles.

It is important to recognize the impact of neighborhood disinvestment and decline on neighborhood access to daily destinations. Travel behavior studies have shown that lowerincome residents travel further distances, and especially for work-based trips. This study shows that even though the lower-income population lives in Urban Detroit neighborhoods characterized by higher-densities, high-connectivity and mixed land uses, the extensive disinvestment within these neighborhoods have increased travel distances to a variety of 
destinations, including to necessary daily amenities. In fact, for Urban Detroit residents, distances to reach shopping, personal services, and leisure destinations are similar to those of residents living in isolated, disconnected, residential neighborhoods in the low-density suburbs. The lower-income eastside Detroit residents face a greater burden, in terms of travel distances, to reach basic daily necessities not because of the urban built environment, but because of the lack of availability of adequate destination choices in proximity to their homes, an outcome shaped by disinvestment.

However, despite these similarities in distances to destinations, on average, the lowdensity Dispersed Suburban respondents travel about twice the distances by car, consume about twice the gasoline (gallons per year), and emit about two times the CO levels associated with automobile travel as compared to the urban respondents. It is thus at multiple dimensions that we can conclude that environmental burdens associated with travel are shaped by class, with higher-income earners disproportionately contributing to negative anthropogenic environmental impacts.

The socio-demographics of vehicle ownership and driving behavior provide a number of important policy insights. At the federal level, this analysis adds support to the recognized ineffective and inequitable structure of the Gas Guzzler Tax, implemented under the Energy Tax Act of 1978. ${ }^{5}$ The Gas Guzzler Tax was introduced in an effort to discourage the manufacture and purchase of fuel-inefficient vehicles. It is placed on manufacturers for sales of vehicles that do not meet a minimum 22.5 miles per gallon. The tax ranges from $\$ 1,000$ per vehicle, for

\footnotetext{
${ }^{5}$ It is recognized that CAFE (Corporate Average Fuel Economy) standards have been more effective in reducing energy consumption by increasing the fuel economy of cars and light trucks. CAFE, enacted by Congress in 1975, was responsible for almost doubling passenger car miles per gallon by 1985 (National Research Council, 2002).
} 
vehicles that have a combined fuel economy of at least $21.5 \mathrm{mpg}$ but less than $22.5 \mathrm{mpg}$, to $\$ 7,700$ per vehicle if the combined fuel economy is less than $12.5 \mathrm{mpg}$ (EPA, 2012).

The Gas Guzzler Tax, however, is not levied on SUVs, minivans and pickup trucks, which in total make-up some $46 \%$ of the registered vehicles in the US (Federal Highway Administration, 2009). These vehicles, a major part of the US passenger vehicle fleet, are known to be larger, heavier, and consume higher levels of fuel, and emit higher levels of pollutants. In addition, as the Detroit region vehicle ownership characteristics show, these vehicles tend to be owned by wealthier populations, who drive over longer distances, disproportionately contributing to the environmental burdens; and yet it is higher-income earners within the region who generally evade this tax.

The socio-demographics of vehicle ownership and travel behavior also provides a more nuanced understanding of transportation infrastructure use, which offers insights to how its financing should be structured. Into 2015, the State of Michigan experienced steep revenue shortfalls combined with rapidly deteriorating infrastructure - including transportation infrastructure - and all occurring during a post-Great Recession economic upswing. The lack of funding for transportation infrastructure is in large part a result of the ruling Michigan Republican Party's move toward a flat tax structure, which has been gaining increasing acceptance across U.S. states, and particularly under Republican administrations (Slemrod, 2006; DGA, 2014). After reducing the state income tax in 2011, in 2012, the Republican administration virtually eliminated state business taxes, and then in 2015 pushed for a further round of income tax cuts, despite statewide infrastructure failures and the fiscal crisis (Senate Fiscal Agency, 2015a; Senate Fiscal Agency, 2015b). In addition, an increasing emphasis by the Republican administration was placed on increasing revenue using sales taxes, consistent with 
the push toward a flat tax structure (Senate Fiscal Agency, 2015a). For instance, in the FY 2014/2015 budget, the combined Michigan Corporate Income and Business Taxes make-up 1.2\% of the state budget, while the Sales and Use Taxes comprise some $42 \%$ of state revenue (Senate Fiscal Agency, 2015b).

With the Michigan Republican Party push toward a flat tax structure, and with the resulting reduction in state revenues, the financing of infrastructure statewide was placed under severe pressure. This is evident with the under-funding of schools in low-income jurisdictions, as in Detroit, growing concerns with safe water provision, as in Flint, and the deterioration of roads, highways and bridges across Michigan. The Michigan Department of Transportation (MDOT, 2015) has long-acknowledged that state roads and bridges have been in poor condition. As Kirk Steudle, Director of MDOT, maintains "It's easy to see why people say we have the worst roads in the country. We put the least amount of emphasis on roads" (Shellenbarger, 2014). The costs of deteriorating roads are also substantial, with added total vehicle operating costs to Michigan motorists associated with driving over poor quality roads being about $\$ 4.8$ billion annually, an annual average of $\$ 686$ in extra vehicle operating costs per motorist. More importantly, the poor conditions of the roads are recognized as contributing to serious traffic crashes, injuries and fatalities (TRIP, 2015).

This Detroit Region study shows the significant spatial differences in automobile ownership and travel patterns. Wealthy suburbanites are much more likely to own vehicles — and larger and heavier vehicles_ - and they travel longer distances, including by driving. The issue of size and weight of vehicles and their impacts on road surfaces is an important consideration, since small increases in vehicle weight result in large increases in road damage (Freeman and Clark, 2002). Higher income populations, therefore, are disproportionately responsible for road 
surface wear and tear, since there is a greater likelihood that they own a vehicle, and a heavier vehicle, and since they travel more, including by driving.

Despite both travel patterns and vehicle ownership characteristics, with the most significant damage on road surfaces being generated disproportionately by the wealthy, extensive effort was placed by the Michigan Republican administration to ensure that the current transportation infrastructure crises be resolved through sales tax increases (Senate Fiscal Agency, 2015a). This has serious efficiency and equity implications - and particularly in the context of who uses transportation infrastructure—-since sales taxes are regressive, disproportionately burdening lower- and more-moderate income earners. Moderate-income earners tend to consume a greater percentage of their income, and hence pay sales tax on a much greater share of income (Slemrod and Bakija, 2008). With the move to flat taxes being increasingly pursued by Republican administrations, as part of their public finance philosophy, the issue of who uses public infrastructure and who pays for its maintenance is an issue of growing national concern.

This intra-regional Detroit socio-ecological study not only reveals the population subgroups that exert the most significant negative anthropogenic impacts on the natural environment from travel, but also provides considerable insight into the design of travel related public charges, and the extent to which sub-groups who utilize resource-intensive travel, and cause travel-related environmental harms more broadly, are exempt from associated costs. There are significant efficiency and equity implications associated with the environmental burdens of travel, which in part have been shaped by policies protecting upper-income groups from the costs of their energy and material-intensive travel behavior.

\section{REFERENCES}


Bailey, L., Mokhtarian, P., Little, A. 2008. The Broader Connection between Public Transportation, Energy Conservation and Greenhouse Gas Reduction. ICF Report submitted to American Public Transportation Association. Fairfax, VA: ICF International.

Bhat, C., Sen, S., Eluru, N. 2009. The impact of demographics, built environment attributes, vehicle characteristics, and gasoline prices on household vehicle holding and use. Transportation Research Part B: Methodological. 43(1), 1-18.

Boyce, R.R., 1963. Myth versus reality in urban planning. Land Economics. 39, 241-251.

Boyce, J. 1994. Inequality as a cause of environmental degradation. Ecological Economics. 11, 169-178.

Boyce, J., Klemer, A., Templet, P., Willis, C. 1999. Power distribution, the environment, and public health: A state-level analysis. Ecological Economics. 29, 127-140.

Brand, C., Preston, J. 2010. ‘60-20 emission'-The unequal distribution of greenhouse gas emissions from personal, non-business travel in the UK. Transport Policy. 17(1), 9-19.

Cao, X., Mokhtarian, P., Handy, S. 2010. Neighborhood design and the accessibility of the elderly: An empirical analysis in Northern California. International Journal of Sustainable Transportation. 4(6), 347-371.

Clawson, M. 1962. Urban sprawl and speculation in suburban land. Land Economics. 38, 99111.

Crutzen. P. 2002. Geology of Mankind. Nature. 415, 23.

Dahl, C., Sterner, T. 1991. Analyzing Gasoline Demand Elasticities-A Survey. Energy Economics. 13(3), 203-210.

DGA. 2014. On Tax Day, The Super-rich Thank Their Lucky Stars for GOP Govs. Washington DC: Democratic Governors Association. Retrieved in April 2015 from:

http://democraticgovernors.org/on-tax-day-the-super-rich-thank-their-lucky-stars-for-gopgovs/\# pbDQLKLPZ5nMuA

Environmental Protection Agency (EPA). 2012. Gas Guzzler Tax. Retrieved from http://www.epa.gov/fueleconomy/guzzler/.

Ewing, R., Cervero, R. 2001. Travel and the Built Environment: A Synthesis. Transportation Research Record. 1780, 87-114.

Freeman, T.E., Clark, T.M. 2002. Performance of Pavements Subject to Higher Truck Weight Limits in Virginia. Transportation Research Record. 1806, 95-100. 
Greening, L., Jeng, H.T., Formby, J., Cheng, D. 1995. Use of region, life-cycle and role variables in the short-run estimation of the demand for gasoline and miles travelled. Applied Economics. 27, 643-656.

Grengs, J. 2012. Equity and the social distribution of job accessibility in Detroit. Environment and Planning B-Planning and Design. 39(5), 785-800.

Hedenus, F., Azar, C. 2005. Estimates of trends in global income and resource inequalities. Ecological Economics. 55, 351-364.

Helling, A. 2000. The effect of residential accessibility to employment on men's and women's travel, paper presented at the Women's Travel Issues Second National Conference, Baltimore, MD.

Holtzclaw, J., Clear, R., Dittmar, H., Goldstein, D., Haas, P. 2002. Location Efficiency: Neighborhood and Socio-Economic Characteristics Determine Auto Ownership and Use Studies in Chicago, Los Angeles and San Francisco. Transportation Planning and Technology. 25(1), 1-27.

Jenerette, D., Wu, W., Goldsmith, S., Marussich, W., Roach, J. 2006. Contrasting water footprints of cities in China and the United States. Ecological Economics. 57, 346-358.

Karathodorou, N., Graham, D., Noland, R. 2010. Estimating the effect of urban density on fuel demand. Energy Economics, 32(1), 86-92.

Kim, J., Brownstone, D. 2013. The impact of residential density on vehicle usage and fuel consumption: Evidence from national samples. Energy Economics. 40, 196-206.

Kim, S. Ulfarsson, G. 2004. Travel mode choice of the elderly: Effects of personal, house-hold, neighborhood, and trip characteristics. Transportation Research Record. 1894, 117-126.

Kotval-K, Z., Vojnovic, I. 2015. The Socio-Economics of Travel Behavior and Environmental Burdens: A Detroit, Michigan Regional Context. Transportation Research Part D: Transport and Environment. 41, 477-491.

Lin, J., Long, L. 2008. What Neighborhood Are You In? Empirical Findings of Relationships Between Household Travel and Neighborhood Characteristics. Transportation 35(6), 739 758.

Matthies, E., Kuhn, S., Kloeckner, C. 2002. Travel mode choice of women: The result of limitation, ecological norm, or weak habit? Environment \& Behavior. 34(2), 163-177.

McGranahan, G., Satterthwaite, D. 2002. The Environmental Dimensions of Sustainable Development for Cities. Geography. 87, 213-226.

McDonald, N. 2005. Does residential density affect the travel "gender gap"? Conference on Research on Women's Issues in Transportation, Transportation Research Board, Washington DC. 
Newman, P., Kenworthy, J. 1989. Gasoline consumption and cities: a comparison of US cities with a global survey. Journal of the American Planning Association. 55, 22-37.

Newman, P., Kenworthy, J 1999. Sustainability and Cities: Overcoming Automobile Dependence. Island Press, Washington DC.

Parshall, L., Gurney, K., Hammer, S., Mendoza, D., Zhou, Y., Geethakumar, S. 2010. Modeling energy consumption and $\mathrm{CO}_{2}$ emissions at the urban scale: Methodological challenges and insights from the United States. Energy Policy. 38, 4765-4782.

Paulley, N., Balcombe, R., Mackett, R., Titheridge, H., Preston, J., Wardman, M.,... White, P. 2006. The demand for public transport: The effects of fares, quality of service, income and car ownership. Transport Policy. 13(4), 295-306.

RERC. 1974. The Costs of Sprawl. Real Estate Research Corporation, Washington DC.

Rees, W. 1992. Ecological footprints and appropriated carrying capacity: What urban economics leaves out. Environment and Urbanization. 4(2), 121-130.

SEMCOG, 1997. Fiscal Impacts of Alternative Land Development Patterns in Michigan. Southeast Michigan Council of Governments, Detroit.

Senate Fiscal Agency. 2015a. The Long and Winding Road: Proposal 1 and Road Funding Reforms (State Notes). Lansing: Senate Fiscal Agency.

Senate Fiscal Agency. 2015b. A History of the Michigan Individual Income Tax Rate. Lansing: Senate Fiscal Agency.

Slemrod, J. 2006. The Role of Misconception in Support for Regressive Tax Reform. National Tax Journal. LIX(1), 57-75.

Slemrod, J., Bakija, J. 2008. Taxing Ourselves: A Citizen's Guide to the Debate over Taxes. MIT Press, Cambridge.

Stead, D. 2002. Relationships between land use, socio economic factors, and travel patterns in Britain. Environment and Planning B-Planning and Design, 28(4), 499-528.

Sterner, T., Dahl, C., Franzen, M. 1992. Gasoline Tax Policy, Carbon Emissions and the Global Environment. Journal of Transportation Economics and Policy, 26(2), 109-119.

$\mathrm{Su}, \mathrm{Q}$. 2011. The effect of population density, road network density, and congestion on household gasoline consumption in U.S. urban areas. Energy Economics, 33(3), 445-452.

U.S. Census Bureau. 2010. Census, 2010-Summary File 1. Washington, DC: Government Printing Office.

Vojnovic, I. 2014. Urban Sustainability: Research, Policy, Politics and Practice. Cities: The International Journal of Urban Policy and Planning. (CRoC). 41, S30-S44. 
Vojnovic, I. \& Darden, J. 2013. Class/racial conflict, intolerance, and distortions in urban form: Lessons for sustainability from the Detroit region. Ecological Economics. 96, 88-98.

Vojnovic, I. (Ed.), 2013. Urban Sustainability: A Global Perspective. Michigan State University Press, East Lansing.

Vojnovic, I. 2006. "Urban Infrastructures" in P. Filion and T. Bunting (Eds.) Canadian Cities in Transition (3rd Edition). Oxford University Press, Oxford. Pp. 123-137.

Vojnovic, I. 2000. Shaping Metropolitan Toronto: a study of linear infrastructure subsidies. Environment and Planning B: Planning and Design. 27, 197-230.

Wackernagel, M., Rees, W. 1996. Our ecological footprint: Reducing human impact on the earth. New Society Publishers, Philadelphia.

Wadud, Z., Graham, D., Noland, R. 2009. Modelling fuel demand for different socio-economic groups. Applied Energy. 86(1), 2740-2749.

WCED (World Commission on Environment and Development). 1987. Our Common Future. Oxford University Press, Oxford.

Wheaton, W.L., Schussheim, M.J. 1955. The Cost of Municipal Services in Residential Areas. U.S. Department of Commerce, Washington DC.

White, T. 2007. Sharing resources: The global distribution of the Ecological Footprint. Ecological Economics. 64, 402-410.

World Bank. 2008. World Development Indicators 2008. Washington DC: World Bank.

Zahabi, S.A.H., Miranda-Moreno, L., Patterson, Z., Barla, P., Harding, C. 2012. Transportation greenhouse gas emissions and its relationship with urban form, transit accessibility and emerging green technologies: A Montreal case. Procedia-Soc. Behav. Sci. 54, 966-978.

Zhou, X., Imra, H. 2011. How does consumer behavior influence regional ecological footprints? An empirical analysis for Chinese regions based on the multi-region input-output model. Ecological Economics. 71, 171-179. 
Appendix A: Breakdown of Categorical Variables

\begin{tabular}{|l|r|r|r|r|r|r|}
\hline Variable & \multicolumn{2}{|c|}{ Urban Detroit } & \multicolumn{2}{c|}{ Compact Suburbs } & \multicolumn{2}{c|}{$\begin{array}{c}\text { Low-density } \\
\text { Suburbs }\end{array}$} \\
\hline & Number & Percent & Number & Percent & Number & Percent \\
\hline RACE & & & & & & \\
\hline White & 18 & 8.3 & 359 & 93.7 & 281 & 88.6 \\
\hline Non White & 199 & 91.7 & 24 & 6.3 & 36 & 11.4 \\
\hline Black & 196 & 90.3 & 7 & 1.8 & 11 & 3.5 \\
\hline Non-Black & 21 & 9.7 & 376 & 98.2 & 306 & 96.5 \\
\hline Total & 217 & 100 & 383 & 100 & 317 & 100 \\
\hline & & & & & & \\
\hline OCCUPATION & & & & & & \\
\hline Employed (for wages) & 83 & 37.2 & 250 & 63.8 & 186 & 58.1 \\
\hline Non-Employed & 140 & 62.8 & 142 & 36.2 & 134 & 41.9 \\
\hline Total & 223 & 100 & 392 & 100 & 320 & 100 \\
\hline
\end{tabular}

Appendix B: Summary of Travel Behavior by Neighborhood Type

\begin{tabular}{|l|r|r|r|}
\hline Household Income & \multicolumn{2}{|c|}{$U D$} & \multicolumn{1}{c|}{ CS } \\
\hline Mode Choice (Average per Respondent) & 13.5 & 16.0 & 5.5 \\
\hline \% Work Trips by Walking & 13.5 & 6.7 & 0.1 \\
\hline \% Work Trips by Transit & 73.0 & 77.3 & 94.4 \\
\hline \% Work Trips by Driving & 23.6 & 21.5 & 6.8 \\
\hline \% Non-Work Trips by Walking & 8.3 & 1.1 & 0.2 \\
\hline \% Non-Work Trips by Transit & 68.1 & 77.4 & 93.0 \\
\hline \% Non-Work Trips by Driving & 23.0 & 20.1 & 6.9 \\
\hline \% All Trips by Walking & 9.8 & 2.8 & 0.2 \\
\hline \% All Trips by Transit & 67.2 & 77.1 & 92.9 \\
\hline \% All Trips by Driving & & & \\
\hline
\end{tabular}




\begin{tabular}{|l|r|r|r|}
\hline \multicolumn{4}{|c|}{ Average Annual Distances in miles (end- and return- destination trips) } \\
\hline Work Trips by Walking & 264.4 & 196.3 & 126.3 \\
\hline Work Trips by Transit & 275.6 & 97.7 & 4.2 \\
\hline Work Trips by Driving & 1663.7 & 2557.6 & 4392.8 \\
\hline Non-Work Trips by Walking & 481.7 & 185.1 & 121.4 \\
\hline Non-Work Trips by Transit & 533.2 & 19.2 & 4.7 \\
\hline Non-Work Trips by Driving & 2564.7 & 1696.6 & 3826.8 \\
\hline All Trips by Walking & 746.1 & 381.4 & 247.7 \\
\hline All Trips by Transit & 808.8 & 116.9 & 8.9 \\
\hline All Trips by Driving & 4228.3 & 4254.2 & 8219.6 \\
\hline & & & \\
\hline
\end{tabular}

Appendix C: Trip Frequency and Average Annual Distances by Mode and Trip Purpose (average per respondent)

\begin{tabular}{|c|c|c|c|c|c|c|c|c|c|}
\hline \multirow[b]{2}{*}{ Income Group } & \multicolumn{3}{|c|}{ Urban Detroit } & \multicolumn{3}{|c|}{ Compact Suburbs } & \multicolumn{3}{|c|}{ Dispersed Suburbs } \\
\hline & Lower & Middle & Upper & Lower & Middle & Upper & Lower & Middle & Upper \\
\hline \multicolumn{10}{|l|}{ Trip Frequency } \\
\hline$\%$ Work Trips by Walk & 16 & 12.6 & 0 & 28.9 & 13.2 & 14.9 & 5.8 & 6.7 & 5.9 \\
\hline$\%$ Work Trips by Transit & 16.5 & 7.7 & 0.5 & 21.2 & 5.8 & 3.5 & 0 & 0 & 0.1 \\
\hline$\%$ Work Trips by Drive & 67.6 & 79.7 & 99.5 & 50.0 & 81.1 & 81.6 & 94.2 & 93.3 & 94 \\
\hline$\%$ Non-Work Trips by Walk & 27.4 & 12.2 & 12.2 & 32.1 & 20.0 & 19.0 & 9.6 & 6.8 & 6.1 \\
\hline$\%$ Non-Work Trips by Transit & 9.2 & 3.1 & 6.9 & 3.7 & 0.4 & 0.6 & 0 & 0.4 & 0.1 \\
\hline$\%$ Non-Work Trips by Drive & 63.4 & 84.7 & 80.9 & 64.2 & 79.6 & 80.4 & 90.4 & 92.8 & 93.8 \\
\hline$\%$ All Trips by Walking & 26.8 & 13.7 & 6.8 & 29.3 & 19.0 & 18.1 & 9.0 & 6.8 & 6.5 \\
\hline$\%$ All Trips by Transit & 10.7 & 4.4 & 7.1 & 8.4 & 2.0 & 1.6 & 0 & 0.4 & 0.2 \\
\hline$\%$ All Trips by Driving & 62.5 & 81.9 & 86.1 & 62.3 & 79.1 & 80.3 & 91.0 & 92.8 & 93.4 \\
\hline \multicolumn{10}{|c|}{ Average Annual Distances to end- and return-destination trips } \\
\hline Work Trips by Walk & 116.8 & 1112.3 & 0.0 & 85.0 & 68.5 & 328.2 & 0.0 & 57.5 & 188.9 \\
\hline Work Trips by Transit & 176.7 & 872.6 & 0.0 & 143.0 & 51.3 & 111.3 & 0.0 & 0.0 & 7.1 \\
\hline Work Trips by Drive & 895.7 & 4298.1 & 6412.2 & 543.2 & 2859.3 & 3159.7 & 664.3 & 3118.9 & 5889.4 \\
\hline Non-Work Trips by Walk & 383.4 & 1011.5 & 427.0 & 288.2 & 201.7 & 132.3 & 39.4 & 225.3 & 92.9 \\
\hline Non-Work Trips by Transit & 412.5 & 1191.6 & 438.0 & 60.1 & 13.0 & 7.0 & 0 & 15.4 & 0.9 \\
\hline Non-Work Trips by Drive & 1996.4 & 5013.6 & 4359.1 & 1554.8 & 1701.1 & 1750.4 & 3316.0 & 3665.4 & 4025.7 \\
\hline
\end{tabular}




\begin{tabular}{|l|r|r|r|r|r|r|r|r|r|}
\hline All Trips by Walking & 500.3 & 2123.8 & 427.0 & 373.2 & 270.2 & 460.6 & 39.4 & 282.8 & 281.8 \\
\hline All Trips by Transit & 589.2 & 2064.2 & 438.0 & 203.1 & 64.3 & 118.3 & 0.0 & 15.4 & 8.0 \\
\hline All Trips by Driving & 2892.1 & 9311.7 & 10771.3 & 2098.0 & 4560.4 & 4910.1 & 3980.3 & 6784.3 & 9915.1 \\
\hline
\end{tabular}

